\title{
The degree of satisfaction of women undergoing surgical repair of prolapse, compared with clinical and urodynamic findings
}

\author{
Carlo Vecchioli-Scaldazza $^{1}$, Carolina Morosetti ${ }^{2}$, Vincenzo Ferrara ${ }^{1}$ \\ ${ }^{1}$ Divisions of Urology, ${ }^{2}$ Clinical Pathology, ASUR, Area vasta n ${ }^{\circ} 2$, Jesi, Italy.
}

\begin{abstract}
Summary Obiective: To assess the degree of satisfaction of women undergoing surgical repair of prolapse, compared with the clinical and urodynamic findings.

Materials and Methods: 72 women hospitalized for pelvic organ prolapse (POP) were enrolled in this prospective study. Patients underwent clinical evaluation and urodynamic study before and 4 months after POP repair. Women were assessed for urinary symptoms by micturition diary and patient perception of intensity of urgency scale. Women were also questioned about defecation and sexual life. POP repair was performed in all cases without the use of a mesh. Subjective evaluation was performed by patient global impression of improvement questionnaire.

Results: 56 women were evaluable. Improvements were found in all micturition symptoms and in particular in voiding symptoms. Feeling of vaginal bulging disappeared in all patients. A slight improvement was found in constipation; $62 \%$ of patients had a normal sexual life but $27 \%$ refrained from sexual activity. Judgement of patients was between "much improved" and "very much improved".

Conclusions: Disappearance of the feeling of vaginal bulging was by far the best result. Improvements were found in most of the symptoms particularly in voiding symptoms and urodynamic findings.
\end{abstract}

KEY WORDS: Genital prolapse; Pelvic organ prolapse surgery; Voiding dysfunction; Urodynamics; Sexual function.

Submitted 9 October 2015; Accepted 15 January 2016

\section{INTRODUCTION}

Pelvic Organ Prolapse (POP) is an abnormal loss of support of one or more of the pelvic organs leading to prolapse into or outside the vagina (1). It is a condition affecting up to $30 \%$ of women (2) and is the most common indication for hysterectomy in women older than 55 years (3). POP may be totally asymptomatic or it may affect the quality of life of women causing physical, psychological and sexual limitations. (2). Women with POP often present a complexity of symptoms in relation to the POP stage and the structures involved (urethra, bladder, uterus, bowels and rectum): urinary symptoms such as incontinence or poor stream, hesitancy, straining to void, incomplete emptying, recurrent urinary tract infec- tions; obstructed defecation with the need to strain or reduce the bulge digitally to defecate; sexual disorders, perineal pain and vaginal bulging (4-7) may be described by the patients. However a lot of the studies evaluated only some specific aspects of the question such as the presence of overactive bladder symptoms (OAB) and/or detrusor overactivity before and after POP repair (8-13), the impact of prolapse surgery on sexual function (14) or anorectal disorders (4).

In this study we considered women with POP to assess changes in symptoms and urodynamic findings before and after prolapse repair, comparing them with the degree of satisfaction of patients.

\section{Materials AND MEthods}

From January 2014 to September 2014, 72 women (mean age 64 years; range 48-82) hospitalized for POP were enrolled in this prospective study. All patients underwent a detailed clinical evaluation including a complete history and physical examination. Patients with neurological disease, pelvic tumors, previously treated with pelvic surgery and particularly with hysterectomy, POP repair, urinary incontinence surgery and radiation therapy, were excluded. POP was evaluated and graded according to pelvic organ prolapse quantification (POP-Q) with the patients in the lithotomy position and maximum straining effort. All patient underwent urodynamic investigation; the study was performed without the prolapse reduction because such reduction can relieve urologic symptoms, which can have an influence on the evaluation of the lower urinary tract function. The study included spontaneous uroflowmetry with post void residual measurement, water cystometry (filling rate $30 \mathrm{ml} / \mathrm{min}$; catheter used: $6 \mathrm{Fr}$ double lumen; patients' position: sitting) with pressure/flow study. Parameters evaluated were maximum flow rate $\left(\mathrm{Q}_{\max }\right)$, post-void residual urine (PVR), cystometric capacity (CC), detrusor pressure at maximum flow $\left(\mathrm{Pdet}_{\mathrm{max}}\right.$ ) and detrusor overactivity (DO). Patients were assessed for urinary symptoms. Urinary storage symptoms (daytime frequency, nocturia and urinary incontinence) were evaluated by 3-day micturition diary; voiding symptoms and post micturition symptoms (hesitancy, straining, terminal 
dribble and feeling of incomplete bladder emptying) were evaluated by individual perception. Urgency was assessed by Patient Perception of Intensity of Urgency Scale (PPIUS) represented by a 5-point scale from 0 (no urgency) to 4 (urge incontinence). Women were also questioned about the impact of POP on their sexual life and defecation. All patients underwent POP repair without the use of a mesh and a standard fascial anterior repair was performed when anterior compartment was involved; the repair was often carried out in conjunction with transvaginal hysterectomy. None of these patients underwent simultaneously surgery for urinary incontinence. All procedures were performed by the same surgeon. Post operative assessment was undertaken at 4 months. Patients repeat urodynamic study, 3-day micturition diary and clinical evaluation. Afterwards, the subjective evaluation of symptoms and the degree of satisfaction of patients after POP repair were assessed with Patient Global Impression of Improvement questionnaire (PGI-I): this is a 7-point scale from "very much improved" (score 1), to "very much worse" (score 7). The research was approved by the Institutional Review Board and the Local Ethics Committee and all patients signed informed consent before starting the study.

Statistical analysis was performed using the MedCalc software package (version14.12.0). Data were expressed as means $\pm \mathrm{SD}$. Comparisons were carried out using the Wilcoxon test for paired samples and chi square test. A p value $<0.05$ was considered significant.

\section{RESULTS}

Of the 72 women initially enrolled, 56 (mean age 63 years, range 48-79) agreed to repeat urodynamic study and clinical evaluation and were evaluable for the study. The vaginal compartment involved and the stage of POP are described in Table 1: a great number of women with POP stage $\mathrm{III}^{\circ}-\mathrm{IV}^{\circ}$ and a greater involvement of the anterior and central vaginal compartment were observed. The surgical procedures undertaken are described in Table 2. Vaginal hysterectomy with anterior repair was the most performed surgical treatment. Patients' characteristics with symptoms and sexual activity expressed in percentages before and after surgery with patients' evaluation of clinical results are summarized in Table 3. Improvements were present in urinary symptoms particularly in voiding symptoms but increased daytime frequency, nocturia, urgency and urinary incontinence persisted respectively in 32, 43, 36 and 41 percent of patients after surgery. A slight improvement was found in constipation but the best clinical result was found in feeling of vaginal bulging, which disappeared after surgery in all patients. Improvements were found in sexual activity with $62 \%$ of women describing a normal sexual life after POP repair but $27 \%$ of patients refrained completely from sexual activity because of discomfort or pain and for fear of damaging POP repair. The degree of satisfaction of patients after surgical POP repair was 1.7 of PGII scale that is a judgment between "much improved" and "very much improved", confirming the efficacy of this treatment in improving the quality of life of patients. Table 4 presents a statistical analysis of urinary symp-
Table 1.

Compartment involvement and stage of prolapse sec. POP-Q.

\begin{tabular}{|lcccc|}
\hline \multicolumn{2}{l}{ Compartment involvement } & \multicolumn{3}{c|}{ Stage (sec. POP-Q) } \\
\hline Anterior & $\mathrm{N}^{\circ}$ & $\mathrm{I}^{\circ}$ & $\mathrm{Il}^{\circ}$ & $\mathrm{II}^{\circ}-\mathrm{IV}^{\circ}$ \\
Central & 56 & 0 & 4 & 52 \\
Posterior & 52 & 0 & 0 & 52 \\
& 4 & 0 & 0 & 4 \\
\hline
\end{tabular}

Table 2.

Procedure undertaken.

\begin{tabular}{|lc|}
\hline Type of procedure & $\mathbf{N}^{\circ}$ \\
\hline Vaginal hysterectomy + anterior repair only & 48 \\
Vaginal hysterectomy + anterior and posterior repair & 4 \\
Anterior repair & 4
\end{tabular}

Table 3.

Patient characteristics, evaluation of clinical results, symptoms and sexual activity before and after surgery.

\begin{tabular}{|lcccc|}
\hline & $\begin{array}{c}\text { Before surgery } \\
\mathbf{N}^{\circ} \text { of patients (\%) }\end{array}$ & $\begin{array}{c}\text { After surgery } \\
\mathbf{N}^{\circ} \text { of patients (\%) }\end{array}$ \\
\hline Patients $\mathrm{n}^{\circ} \quad 56$ & & & & \\
Age & $63(48-79)$ & & & \\
BMI $\quad 25.4(18.5-33.3)$ & & & & \\
PGI-I $\quad 1.7$ & & & & \\
\hline Symptoms & 36 & $(64)$ & 18 & $(32)$ \\
Increased daytime frequency & 33 & $(59)$ & 24 & $(43)$ \\
Nocturia & 33 & $(59)$ & 20 & $(36)$ \\
Urgency & 27 & $(48)$ & 23 & $(41)$ \\
Urinary incontinence & 47 & $(84)$ & 9 & $(16)$ \\
Hesitancy & 29 & $(52)$ & 3 & $(5)$ \\
Straining & 36 & $(64)$ & 9 & $(16)$ \\
Terminal dribble & 44 & $(78)$ & 9 & $(16)$ \\
Feeling of incomplete bladder emptying & 17 & $(30)$ & 15 & $(27)$ \\
Constipation & 0 & $(0)$ & 0 & $(0)$ \\
Gas or solid stool incontinences & 52 & $(93)$ & 0 & $(0)$ \\
Vaginal bulge & & & & \\
Sexual activity & 10 & $(18)$ & 35 & $(62)$ \\
Normal sexual activity & 35 & $(62)$ & 0 & $(0)$ \\
Sexual activity affected by prolapse & 5 & $(9)$ & 0 & $(0)$ \\
No sexual activity because of prolapse & 5 & & 15 & $(27)$ \\
No sexual activity because of surgery & & & & \\
No sexual activity for other reasons & & & 6 & $(11)$ \\
(widows, sisters) & 6 & $(11)$ & & \\
\hline
\end{tabular}

Table 4.

Urinary symptoms evaluated with statistical analysis.

\begin{tabular}{|lccc|}
\hline & Before surgery & After surgery & p \\
\hline Urinary symptoms & & & \\
Daytime frequency & $9.8 \pm 2.48$ & $8.36 \pm 1.77$ & $<0.0001$ \\
Nocturia & $1.13 \pm 1.3$ & $0.59 \pm 0.75$ & 0.0229 \\
Urgency & $1.34 \pm 1.21$ & $0.64 \pm 0.81$ & 0.0002 \\
Urinary incontinence & $1.18 \pm 1.43$ & $0.54 \pm 0.94$ & 0.1092 \\
Hesitancy & 47 & 9 & $<0.0001 *$ \\
Straining & 29 & 3 & $<0.0001 *$ \\
Terminal dribble & 36 & 9 & $<0.0001 *$ \\
Feeling of incomplete emptying & 44 & 9 & $<0.0001 *$ \\
\hline Statistical analysis performed with Wilcoxon test for paired samples except (*) & \multicolumn{4}{l}{} \\
performed with chi square test. & \multicolumn{4}{|l}{} \\
\hline
\end{tabular}


Table 5.

Urodynamic findings before and after surgery.

\begin{tabular}{lccc}
\hline & Before surgery & After surgery & p \\
\hline Urodynamic parameters & & & \\
$Q_{\max }(\mathrm{ml} / \mathrm{S})$ & $12.29 \pm 5.79$ & $13.88 \pm 4.80$ & 0.0071 \\
PVR $(\mathrm{ml})$ & $64.94 \pm 59.39$ & $42.65 \pm 33.35$ & 0.0405 \\
CC $(\mathrm{ml})$ & $435.69 \pm 178.84$ & $420.88 \pm 166.83$ & 0.0635 \\
D0 $\left(n^{\circ}\right.$ of patients $)$ & 11 & 6 & $0.1879 *$ \\
Pdet $_{\max }(\mathrm{CmH} 20)$ & $36.71 \pm 20.18$ & $30.65 \pm 10.30$ & 0.0029 \\
\hline
\end{tabular}

DO expressed in number of patients. Statistical analysis performed with Wilcoxon test for paired samples except $\left(^{*}\right)$ performed with chi square test.

toms. All parameters evaluated except urinary incontinence, showed statistically significant improvements. Urodynamic parameters analyzed are reported in Table 5. A significant increase in Qmax with a reduction of PVR were found at uroflowmetry. CC did not show a significant change in cystometry but a reduction in the values of PdetQmax was found in pressure/flow study. The number of patients with DO decreased without a statistical significance.

\section{Discussion}

We evaluated the degree of satisfaction of the women using PGI-I questionnaire because it included an overall assessment of the outcome of the surgical therapy. We also evaluated, before and after POP repair, variations in individual symptoms using both statistical investigation and variations in percentages. This method enabled us to observe how the statistically significant reduction of a symptom was often associated with the persistence of the same symptom in a sizeable percentage of patients.

Improvement in the urinary symptoms particularly in voiding and post micturition symptoms was found after POP repair. However, while micturition symptoms decreased, the number of symptomatic patients was still sizeable: 32\% out of 64 (daytime frequency) and 43\% out of 59 (nocturia). Urgency evaluated by PPIUS significantly improved, but $36 \%$ out of 59 of patients were still symptomatic. OAB symptoms usually improve after POP surgical repair or replacement of pessaries $(11,8,15)$, but they can remain after treatment due to other causes as ischemic changes produced by aging (16); furthermore, about $20 \%$ of women develop OAB after surgery (9). There is no agreement about a relationship between prolapsed compartment, stage and symptoms. Some authors believe that the involvement of the anterior compartment is the main cause of $\mathrm{OAB}$ symptoms $(17,15)$ : the distension of stretch receptors of the urothelium due to the descent of the trigone into the anterior vaginal wall and the denervation of autonomic nerve supply to the detrusor muscle caused by the urethral obstruction are considered the main causes $(12,15,18,19-21)$. In this study the significant improvement shown by voiding and post micturition symptoms were due to the improvement of obstruction caused by POP repair. The increase of $Q_{\max }$, the reduction of PVR and the reduction of pdet $Q_{\max }$ at urodynamic study confirm these results. Several studies have shown that obstruction is frequently observed in women with severe prolapse (22-24) and
POP repair produces improvement in both obstruction and urodynamic findings (8, 16, 22-25). However, no significant change in urodynamic findings after surgery were recorded by Stanton SL et al. (27) and Rosenzweig et al. (28). Ling et al. (29), in their research, pointed out that $70 \%$ of patients with severe POP and elevated PVR with voiding difficulty symptoms had urodynamic evidence of obstruction only in one third of cases. Unsatisfactory results after POP repair can be found in patients with impaired detrusor contractility, such as in three cases we observed. Decreased detrusor contractility may depend on aging of patients as well as the persistence of the obstruction as occurs in men with prostatic hypertrophy. DO decreased after surgery but not significantly in this study in line with the results of other authors (13). As for $\mathrm{OAB}$, following $\mathrm{POP}$ repair, DO can improve or persist when the causes are different from prolapse or even arise de novo, due to the surgery.

Feeling of vaginal bulging was found in 93\% of patients before surgery and four months after POP repair it disappeared in all women: this is the best surgical outcome. Vaginal bulging is related to the POP stage and 52 out of 56 evaluable women showed a stage III-IV.

Disappearance of vaginal bulging was particularly emphasized by patients during clinical evaluation performed 4 months after surgery. A significant correlation between POP stage and vaginal bulging was described by Marijke et al. (17) and vaginal bulging was considered the main aspect related to prolapse by Pakbaz et al. (30). Constipation was the principal negative factor of defecation, whereas no cases of gas or solid stool incontinences was observed. This finding is probably related to the only 4 patients with involvement of the posterior compartment present. A relation between posterior compartment prolapse and bowel disorders including incontinence of flatus, were described by Marijke et al. (17) and Jelovsek et al. (4). After POP repair only 2 out of 17 women were asymptomatic but constipation is a symptom also found in patients with involvement of different vaginal compartments; furthermore, it is unlikely that prolapse is a significant contributor to constipation (4). Normal sexual activity improved after POP repair with $62 \%$ of women reporting a normal sexual life compared to $18 \%$ observed before surgery. This data is in agreement with findings of other authors $(31,32)$. An interference of POP with sexual activity was reported by Pakbaz et al. (30) in more than $30 \%$ of women. We performed POP repair without the use of mesh. The use of mesh is neither associated with a worsening in sexual function nor with an increase in the novo dyspareunia compared with traditional colporraphy (14). The occurrence of dyspareunia after mesh is described in a percentage ranging between $5 \%$ and $28 \%$. (33). However $27 \%$ of patients in our experience refrained completely from sexual activity because of discomfort or pain as well as of the fear of damaging POP repair. Many studies have been carried out on POP and we now have access to a lot of data. Various aspects of POP have been analysed for a better understanding especially of the cause of symptoms, their relationship with the degree of prolapse, the prolapsed compartment and the effect that surgery can have on symptoms. The complexity of symptoms and the dynam- 
ics of the vaginal compartments after surgery make it difficult to evaluate the effects of surgery $(34,35)$. Furthermore, a simple anatomical correction of prolapse may not be able to improve the symptoms (36). There are still many different opinions about prolapse and data are often contradictory. To a large extent this could be attributed to the great variability of patients. In our study, however, nearly all the patients presented $\mathrm{III}^{\circ}-\mathrm{IV}^{\circ}$ grade prolapse of anterior and central compartment. However, hysterectomy performed in almost all cases of POP repair may be a potential source of bias and the few cases with involvement of the posterior compartment can explain the few defecation symptoms reported by patients. Furthermore, the older age of women enrolled could itself be a cause of symptoms.

\section{Conclusions}

Improvements in different percentages were found in most of the symptoms considered but the disappearance in all patients of the feeling of vaginal bulging represents the best surgical outcome. Significant improvements were also found in voiding symptoms and urodynamic findings.

\section{References}

1. Milsom I, Altman D, Lapitan MC, et al. Epidemiology of urinary (UI) and fecal (FI) incontinence and pelvic organ prolapse (POP). In: Abrams P, Cardozo L, Khoury S, Wein A, editors. Chapter 1 in Epidemiology in Incontinence 4th International Consultationon Incontinence, 4th edition, Paris, july 5-8 2008. Health Publication Ltd; 2009.

2. Samuelsson EC, Arne Victor FT, Tibblin G, Svardsudd KF. Signs of genital prolapse in a Swedush population of women 20 to 59 years of age and possible related factors. Am J. Obstet Gynecol. 1999; 180:299-305.

3. Wilkox LS, Koonin LM, Pokras R, et al. Hysterectomyin the United States 1988-1990. Obstet Gynecol. 1994; 83:549-555.

4. Jelovsek JE, Barber MD, Paraiso MFR, Walters MD. Functional bowel and anorectal disorders in patients with pelvic organ prolapse and incontinence. Am J Obstet Gynecol 2005; 193:2105-2111.

5. Mouritsen L. Classification and evaluation of prolapse. Best Pract Res Clin Obstet Gynaecol. 2005; 19:895-911.

6. Rogers GR, Villarreal A, Kammerer-Doak D, Qualls C. Sexual function in women with and without urinary incontinence and/or pelvic organ prolapse. Int Urogynecol J Pelvic Dysfunction. 2001; 12:361-365.

7. Albers LL, Borders N. Minimizing genital tract trauma and related pain following spontaneous vaginal birth. J Midwifery Womens Health. 2007; 52:246-253.

8. Basu M, Duckett JRA. Effect of prolapse repair on voiding and relationship to overactive bladder and detrusor overactivity. Int Urogynecol J. 2009; 20:499-504.

9. Dietz-Itza I, Alpitarte I, Becerro A, Sarasqueta C. Incidence of overactive bladder after vaginal hysterectomy and associated repairs for pelvic organ prolapse. Gynecol Obstet Invest. 2009; 68:65-70.

10. Zheng Yong Yuan, Hong Shen. Pelvic organ prolapse quantification in women referred with overactive bladder. Int Urogynecol J. 2010; 21:1365-1369.
11. Digesu A, Salvatore S, Chaliha C, et al. Do overactive bladder symptoms improve after repair of anterior vaginal wall prolapse? Int Urogynecol J. 2007; 18:1439-1443.

12. Patil A, Duckett J. Effect of prolapse repair on voiding and bladder overactivity. Curr Opin Obstet Gynecol. 2010; 22:399-403.

13. De Boer TA, Salvatore S, Cardozo L, et al. Pelvic organ prolapse and overactive bladder. Neurourol Urodyn. 2010; 29:30-39.

14. Dietz V, Maher C. Pelvic organ prolapse and sexual function. 2013; 24:1853-1857.

15. Serati M, Salvatore S, Siesto G, et al: Urinary symptoms and urodynamic findings in women with pelvic organ prolapse: is there a correlation? Results of an artificial neural network analysis.Europ Urol. 2011; 60:253-260.

16. Fletcher SG, Haverkorn RM, Yan J, et al. Demographic and urodynamic factors associated with persistent $O A B$ after anterior compartment prolapse repair. Neurourol Urodyn. 2010; 29:1414-1418.

17. Slieker-Ten Hove MC, Pool-Goudzvaard AL, Eijkemans MJC, et al: The prevalence of pelvic organ prolapse symptoms and signs and their relation with bladder and bowel disorders in a general female population. Int Urogynecol J Pelvic Floor Dysfunct. 2009; 20:10371045.

18. Gosling JA, Gilpin SA, Dixon JS, Gilpin GJ. Decrease in the autonomic innervation of human detrusor muscle in outflow obstruction. J Urol. 1986; 136:501-504.

19. Harrison SC, Hunnam GR, Farman P, et al. Bladder instability and denervation in patient with bladder outflow obstruction. Br J Urol. 1987; 60:519-522.

20. Harrison SC, Ferguson DR, Doyle PT. Effect of bladder outflow obstruction on the innervation of the rabbit urinary bladder. $\mathrm{Br} \mathrm{J}$ Urol. 1990; 66:372-379.

21. Sibley GN: The physiological response of the detrusor muscle to experimental bladder outflow obstruction in the pig. Br J Urol. 1987; 60:332-336.

22. Romanzi LJ, Chaikin DC, Blaivas JG: The effect of genital prolapse on voiding. J Urol 1999;161:581-586.

23. Groutz A, Blaivas JG, Chaikin DC. Bladder outlet obstruction in women: definition and characteristics. Neurourol Urodyn. 2000; 19:213-220.

24. Nguyen JK, Bhatia NN. Resolution of motor urge incontinence after surgical repair of pelvic organ prolapse. J Urol. 2001; 166:2263-2266.

25. Robinson D, Staskin D, Laterza RM, Koelbl H. Defining female voiding dysfunction:ICI-RS 2011. Neurourol Urodyn. 2012; 31:313316.

26. Romanzi LJ, Chaikin DC, Rosenthal JR, et al. The effects of a pessary on parameters of micturition in women with severe genital prolapse. J Urol. 1998; 159:216-21

27. Stanton S, Hilton P, Norton C, Cardozo L. Clinical and urodynamic effects of anterior colporraphy and vaginal hysterectomy for prolapse with and without incontinence. Br J Urol. 1982; 89:459-463.

28. Rosenzweig BA, Soffici AR, Thomas S, Bhatia NN. Urodynamic evaluation of voiding in women with cystocele. J Reprod Med. 1992; 37:162-166.

29. Ling C, Chang Y, Lin Y, Chang S. Significance of bladder trabeculation in postmenopausal women with severe pelvic organ prolapse: clinical and urodynamic assessments. Menopause. 2013; 20:813:817. 
30. Pakbaz M, Rolfsman E, Mogren I, Lofgren M. Vaginal prolapseperceptions and healthcare-seeking behaviour among women prior to gynaecological surgery. Acta Obstet Gynecol. 2011; 90:11151120.

31. Ghielmetti T, Kuhn P, Dreher EF, Kuhn A. Gynaecological operations: do they improve sexual life? Eur J Obstet Gynecol Reprod Biol. 2006; 129:104-110.

32. Komesu YM, Rogers RG, Kammerer-Doak DN, et al. Posterior repair and sexual function. Am J Obstet Gynecol. 2007; 197:101e1$101 e 6$.

33. Milani R, Salvatore S, Soligo M, et al. Functional and anatomi- cal outcome of anterior and posterior vaginal prolapse repair with prolene mesh. BJOG. 2005; 112:107-111.

34. Hullfish KL, Bovbjerg VE, Gibson J, Steers WD. Patient-centered goals for pelvic floor dysfunction surgery: what is success, and is it achieved? Am J Obstet Gynecol. 2001; 187:88-92.

35. Crafoord K, Sydsjo A, Johansson T, et al. Factors associated with symptoms of pelvic floor dysfunction six years after primary operation of genital prolapse. Acta Obstet Gynecol. 2008; 87:910-915.

36. Basu M, Duckett J. The association of changes in opening detrusor pressure with the resolution of overactive bladder symptoms after repair of pelvic organ prolapse. Neurourol Urodyn. 2011; 30:595-598.

\section{Correspondence}

Carlo Vecchioli-Scaldazza, MD (Corresponding Author) cascave@alice.it

Division of Urology, ASUR, Area Vasta n², Jesi, Italy

Corso Cavour 66, 62100 Macerata, Italy

Carolina Morosetti,MD

c.morose@libero.it

Clinical Pathology, ASUR, Area Vasta n², Jesi, Italy

Vincenzo Ferrara, MD

vincenzoferrara4@gmail.com

Division of Urology, ASUR, Area Vasta n², Jesi, Italy 